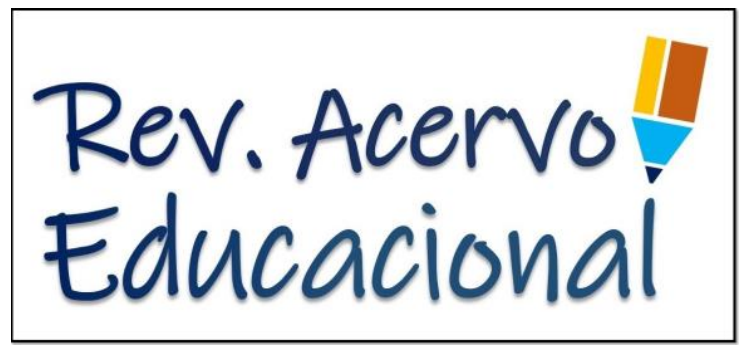

RELATO DE EXPERIÊNCIA

Recebido em: 11/2019

Aceito em: 12/2019

Publicado em: 2/2020

\title{
Rebuscando o Português: por uma neuroplasticidade diferente
}

\author{
Rescuing Portuguese: for a different neuroplasticity \\ Rescatando al portugués: por una neuroplasticidad diferente
}

Louise Bogéa Ribeiro $^{1 *}$, Jussara da Silveira Derenji1, Manoel da Silva Filho1

\begin{abstract}
Resumo: Por meio de um relato de experiência, demonstramos um exemplo de ação educativa e inclusiva, direcionada a jovens de escola pública de ensino médio no contexto de iniciação científica que vem sendo praticada na Casa da Ciência do Hemocentro de Ribeirão Preto - SP, em colaboração com a Universidade de São Paulo (USP). Como justificativa para o desenvolvimento do presente estudo, tem-se que a iniciação científica deve ser vista como uma ferramenta que pode melhorar a qualidade da Educação em diferentes campos do conhecimento, neste caso, em particular, referente ao processo de ensino aprendizagem de língua portuguesa. Para tanto, a metodologia de pesquisa empregada no presente estudo tratou-se do relato de experiência que se traduz em um texto acerca de dada experiência que possa vir a colaborar de maneira proeminente para um determinado campo de atuação. Utilizamos o software CalcuLetra cujo algoritmo é capaz de determinar a relativa dificuldade de compreensão textual para promover a assimilação de palavras incomuns da língua e sua posterior incorporação no repertório linguístico dos educandos. Concluímos que a utilização de estratégias metacognitivas beneficia a aprendizagem, promovendo o desenvolvimento da cognição e funções psicológicas superioras independentemente da idade e limitações advindas do próprio sujeito, conseguindo superá-las.
\end{abstract}

Palavras-chave: Ensino-aprendizagem, Entropia informacional, Comunicação, Processos cognitivos.

Abstract: Through an experience report, we showed an example of educational and inclusive action, directed to young people from public high school in the context of scientific initiation that has been practiced at the House of Science of Ribeirão Preto-SP, in collaboration with the University of São Paulo (USP). As justification for the development of this study, the scientific initiation can be seen as a tool that can be incorporated into the procedure of improving the quality of education in different fields of knowledge, in this particular case, referring to the teaching process in Portuguese language learning. Therefore, the research methodology employed in the present study was the experience report that translates into a text about a given experience that may contribute prominently to a particular field of action. We used the CalcuLetra software capable of determining the relative difficulty of textual comprehension to promote the assimilation of unusual words of the language and their subsequent incorporation into the students' linguistic repertoire. We concluded that the use of metacognitive strategies benefits learning, promoting the development of cognition and superior psychological functions regardless of age and limitations arising from the subject himself in order to overcome them.

Keywords: Teaching and learning, Information entropy, Communication, Cognitive processes.

1 Universidade Federal do Pará (UFPA), Museu da UFPA, Belém - PA. *E-mail: loubog8@gmail.com 
Resumen: Através de un informe de experiencia, demostramos un ejemplo de acción educativa e inclusiva, dirigida a los jóvenes de la escuela secundaria pública en el contexto de la iniciación científica que se practica en la Casa de la Ciencia del Hemocentro Ribeirão Preto, en colaboración con Universidad de São Paulo (USP). Como justificación para el desarrollo de este estudio, ha sido que la iniciación científica debe ser vista como una herramienta que puede mejorar la calidad de la educación en diferentes campos del conocimiento, en este caso, en particular, refiriéndose al proceso de enseñanza del aprendizaje del idioma portugués. Por lo tanto, la metodología de investigación utilizada en el presente estudio fue el informe de experiencia que se traduce en un texto sobre una experiencia dada que puede contribuir de manera prominente a un campo de acción particular. Utilizamos el software CalcuLetra capaz de determinar la dificultad relativa de la comprensión textual para promover la asimilación de palabras inusuales del idioma y su posterior incorporación al repertorio lingüístico de los estudiantes. Concluimos que el uso de estrategias metacognitivas beneficia el aprendizaje, promoviendo el desarrollo de la cognición y funciones psicológicas superiores, independientemente de la edad y las limitaciones derivadas del propio sujeto, logrando superarlas.

Palabras clave: Enseñanza y aprendizaje, Entropía informativa, Comunicación, Procesos cognitivos.

\section{INTRODUÇÃO}

O atual quadro educacional brasileiro é alvo de críticas, pautadas no desempenho insatisfatório de discentes no Exame Nacional do Ensino Médio (ENEM) e em outros exames nacionais, a exemplo da Prova Brasil, do Sistema de Avaliação da Educação Básica (SAEB) e no Programa de Avaliação Internacional (PISA). Os estudantes demonstram dificuldades principalmente no que diz respeito à compreensão escrita, o que pode ser resultado da utilização de métodos instrucionais ou avaliativos inadequados, durante a preparação da formação estudantil (SILVA AB, 2017).

Em prol da formação mais qualificada, o ato de ler não pode ser negligenciado na sala de aula, respeitando-se as limitações advindas do próprio sujeito. As competências exigidas para as habilidades de leitura e escrita precisam ser enfatizadas no ambiente escolar, dando autonomia ao estudante no exercício da sua cidadania, para a formação da sua própria identidade, mediante as relações sociais e culturais. Ao deparar-se com experiências novas, o nosso sistema nervoso tem a capacidade de reorganizar os circuitos neurais, resultando na aprendizagem ou ao que podemos chamar de neuroplasticidade (REIS A, et al., 2009).

Práticas pedagógicas direcionadas podem estimular o fenômeno da neuroplasticidade ao promover a aquisição de novos conhecimentos e habilidades, gerando mudanças comportamentais (GUERRA LB, 2011). Por muitas décadas, observou-se que investigações no campo da aprendizagem concentram-se nas competências cognitivas, bem como nos fatores motivacionais, ambos podendo ser considerados como dois fatores determinantes no sucesso do processo de ensino-aprendizagem.

$\mathrm{Na}$ década de 1970, houve o surgimento de uma terceira categoria de variáveis, que se trata dos processos metacognitivos, estes que coordenam as capacidades cognitivas emaranhadas na memória, leitura, entendimento de textos, etc (GUERRA LB, 2011). A esse conhecimento, assim como a capacidade de planejar, de dirigir a compreensão e de avaliar o que foi aprendido, atribui-se a designação de metacognição. Salienta-se que fatores relativos à idade, formação e ensino têm ligação direta com o desenvolvimento de habilidades metacognitivas para atingir a compreensão (RIBEIRO C, 2003).

A ausência de sucesso de determinados estudos realizados com a finalidade de promover o uso de estratégias e/ou alterações, nas já usadas, e a averiguação de diferenças expressivas notadas no desempenho escolar, não somente em cargo do uso de estratégias cognitivas, porém, igualmente de estratégias metacognitivas, induziu certos autores a concluírem que os bons educandos são mais capazes tanto no uso de estratégias para contrair, organizar e usar o seu conhecimento, como igualmente na regulação de seu avanço cognitivo (JOLY MC, et al., 2006). Alguns estímulos ao comportamento 
metacognitivo do leitor são textos anômalos e ambíguos, podendo ser utilizadas a inversão da ordem direta, voz ativa ou passiva e texto lacunado (teste cloze), entre outros.

O projeto "Rebuscando o Português: por uma neuroplasticidade diferente", desenvolvido com discentes da Escola Estadual Jardim Paiva II, em Ribeirão Preto-São Paulo, dividido entre 10 encontros no segundo semestre de 2017, e inserido no programa Pequeno Cientista da Casa da Ciência do Hemocentro de Ribeirão Preto, em colaboração com a Universidade de São Paulo-USP, teve o objetivo de ampliar o repertório vocabular dos participantes, mediante a utilização de estratégias metacognitivas, para a aquisição de vocábulos incomuns do português.

Para quantificar a decodificação semântica textual, utilizamos o software CalcuLetra (RIBEIRO LB, 2018), disponível em https://github.com/LouiseBogea/CalcuLetra, cujo algoritmo determina uma medida probabilística da dificuldade de compreensão textual e relativa complexidade em aspectos semânticocomunicacionais, com base na teoria da informação (SHANNON CE, 1948; D’ALFONSO S, 2010). Confirmamos que palavras incomuns (baixa entropia informacional) têm efeitos causadores de ruído no processamento mental dos participantes, apesar de serem neurotípicos e fluentes na língua (RIBEIRO LB, et al., 2019).

As ações do projeto resultaram em diferentes formatos textuais, recitais dos textos escritos, encenações teatrais, vídeos das performances (teatro, contação de histórias), jogos educativos (sorteio de palavras) e o "Minidicionário de palavras quase desconhecidas da língua portuguesa". Nosso objetivo era o de validar a aplicabilidade do conceito de metacognição na educação, bem como seus benefícios para 0 desenvolvimento da cognição e funções psicológicas superioras.

Para tanto, buscou-se demonstrar a função das estratégias metacognitivas frente à potencialização da aprendizagem no Ensino Médio, no desenvolvimento pelo aluno de meios eficientes para atuar com a informação decorrente do meio e com os próprios procedimentos de pensamento. Assim, é possível a incorporação do conteúdo no cotidiano dos estudantes, contribuindo na formação de usuários da língua críticos, capazes de questionar e comparar informações, gerando opinião, conhecimento e consequente participação na comunidade em que estejam inseridos.

\section{RELATO DE EXPERIÊNCIA}

Para a realização do projeto, fez-se necessário conhecer a realidade do grupo, respeitando seus valores e cultura, para a superação das desigualdades sociais existentes, o que promoveu a integração ensinopesquisa-extensão, bem como a relação sociedade e meio acadêmico. Na medida em que os estudantes assimilavam os vocábulos incomuns advindos dos textos classificados como de difícil compreensão pelo CalcuLetra conseguiam inseri-los em suas produções.

Quadro 1 - Vocábulos selecionados do banco de dados do CalcuLetra.

\begin{tabular}{|c|c|c|c|c|c|}
\hline Opróbrio & Tênul & Alastrar & Eflúvio & Pachorrento & Comprazimento \\
\hline Janota & Pândego & Obulia & Admoesta & Perscrutar & Propalar \\
\hline Perdulário & Idiossincrasia & Engodar & Taciturno & Chona & Laborações \\
\hline Laute & Devir & Chistoso & Lídima & Valências & Debuxo \\
\hline Tergiversar & Preito & Serédio & Sapiência & Arrojo & Precetora \\
\hline Rubicunda & Aportemos & Abastança & Gutuar & Empriterno & Regiamente \\
\hline Adstrito & Prefungente & Profira & Preceito & Beócio & Benemérito \\
\hline
\end{tabular}

Fonte: Ribeiro LB, et al., 2019. 
"Hoje vejo que minha vida é a ruar. Então queria perscrutar meu coração. Porém sempre pachorrento e tênul. Fui atrás de ser pândego. Em uma das minhas preces sempre me sentindo supérfluo. Quando finalmente achei, acordei do coma." (Exemplo 1).

"A colisão entre eles tirou ela do inanimado de um equívoco opróbrio que passaste minutos antes tendo um paradoxo de parecer. E foi assim, amor à primeira vista. Quem diria que ele se apaixonava por uma janota, era uma quimera oscilante. Naquele momento ele queria se abduzir, mas era vistoso perdulário e não conseguia passar desapercebido por sua austeridade. E naquele certo momento meticuloso capcioso e laute tentava ser Ihano sem tergiversar, agarrou-se a ela em oscular, mesmo ela se sentindo ínfima rubicunda. E foi em um apenas oscular que poderia procrastinar se tornaram adstrito e irreparáveis." (Exemplo 2).

"Se olhe no espelho menina, tu és a idiossincrasia da beleza. Esse eflúvio de juventude, com esse seu jeito chistoso, seu jeito pachorrento, tênul e taciturno de ser é o que tem de melhor. O colorário de sua baixa estima está aí, deixe de ser tão belicoso contigo, tu és como tem que ser. Esta obulia está tomando conta de seus pensamentos impedindo que eles fiquem absortos. Tu tens o dom de fazer todos se afeiçoarem, sei também que queria ter um jeito afável de ser, mas não consegues, na verdade você tem o jeito Ihano, no entanto não tem o reconhecimento que queres. Está sempre frustrada, fazes o que queres, tenta ser afim das outras pessoas suas emoções estão injuriadas, queres tirar essa ânsia do peito. No fundo quer ser apenas normal nessa sociedade em que a beleza é o que mais importa." (Exemplo 3).

"O dia em que morri não senti dor alguma. Todos aqueles que ao redor do meu cadáver. Gelado choravam, não sabiam um terço da dor que por Anos carreguei. $A$ dor que minha morte causou a algumas pessoas, a mim nada mais era do que um alívio. Alívio de uma vida que já não mais existia, de uma admoesta deliberada inteiramente aos outros. Esse logro iniciou-se há dois anos numa noite fria, eu estava pândega, esse foi o verdadeiro luto...da minha vida. Minha vida não esgotouse em uma Avenida, cercada por uma ponte a ruar com oito Rodas de um caminhão. A última gota de vida que restava-se extinguiu-se naquela noite de diz 25/08, com gritos, olhares de desejo, tapas, a dor... Aquela foi a dor que tirou a alma que existia no meu corpo, e por fim meu estupro." (Exemplo 4).

"Lá ia o janota pela avenida, quando avistou a frugal moradia da amada do seu coração. Todo pândego resolveu perscrutar pelas janelas se ela estava em casa, inesperadamente apareceu na janela o avô da menina. Percebendo que ele era um velho pachorrento, fez-se de pacóvio e começou a engodar o senhor que, apesar de taciturno era muito esperto e Ihano e disse ao janota: - Não é de minha balda meu caro jovem, mas preciso admoesta-lo: não engane o tênul coração da minha neta com palavras supérfluas.

Diante do inusitado o rapaz exclamou: Poxa, fiquei surpreso vejo que és uma sumidade." (Exemplo 5).

"São palavras sinceras ou um jogo de palavras? O truque que brinca com o psicólogo. A magia que nos conduz à comoção. Manipulado por um poeta. O que você leu foi programado? Como um ditado popular. Talvez uma fábula com moral. A mensagem estava atrás das cortinas esperando pelas palmas, sorrisos e gritos. Ele te fisgou com poucas palavras sendo ou não controladas. Você sorriu, certo? Foi real no irreal, na criação bem escrita." (Exemplo 6). 
Almejou-se favorecer um processo de ensino-aprendizagem na concepção de linguagem interacionista, funcional e discursiva, com uma visão reflexiva dos usos reais da língua, inseridos em contextos sociocomunicativos que fazem parte do cotidiano dos discentes, e, por conseguinte, assistir na formação do aluno, gerando cidadania. A partir das ações do projeto, realizou-se o I Concurso de Conhecimento de Palavras em Português (CCPP), inserido no programa educacional Adote um Cientista também da Casa da Ciência. O CCPP, competição saudável acerca dos vocábulos incomuns da língua, foi destinado a discentes do ensino médio, matriculados nas escolas públicas e privadas de Ribeirão Preto - SP.

No 26을 Mural da Casa da Ciência, os orientandos tiveram a oportunidade de divulgar os conhecimentos aprendidos, cujo registro pode ser acessado pelo site oficial e Youtube da Casa (CASA DA CIÊNCIA, 2017). Os orientadores, por sua vez, avaliaram os demais trabalhos realizados durante o semestre. No espaço reservado ao projeto, foram disponibilizados ao público visitante o minidicionário de palavras incomuns e o jogo de sorteio de palavras utilizado no concurso.

\section{DISCUSSÃO}

A transmissão do conhecimento científico em uma linguagem acessível, com o aproveitamento de recursos e metodologias que possam facilitar o diálogo e ajustar o discurso, precisa ser incentivada para a assimilação de descobertas e colaborar com a educação inclusiva e diversidade (RIBEIRO LB, et al., 2019). Observa-se que, embora haja uma polêmica em torno do conceito de metacognição, vem sendo analisada a sua importância para a maximização da aprendizagem. Os treinos que consideram além de ações cognitivas, atividades metacognitivas, vêm trazendo melhores resultados em termos de aprendizagem escolar. Frente a isto, tem-se que a metacognição, referente designadamente à aprendizagem, pode vir a assumir duas acepções: a avaliação de recursos e a metacognição em ação (ALMEIDA LS, et al., 2008).

Neste contexto, a avaliação de recursos cognitivos alude-se a reflexões individuais acerca da condição dos conhecimentos e capacidades cognitivas sobre as particularidades das atividades que entusiasmam a dificuldade cognitiva e acerca das estratégias disponíveis para a concretização da atividade. A metacognição em ação alude-se a reflexões individuais sobre a organização e planejamento da ação antes do começo da atividade, nos ajustes que se realizam enquanto se concretiza a atividade, bem como nas revisões imprescindíveis para a averiguação dos resultados alcançados (MARINI JA e JOLY MCRA, 2008).

Validamente, docentes atuam como intercessores na aprendizagem, atuando como promotores da autorregulação ao permitirem a manifestação de planos individuais. Estes assumem então uma função essencial no preparo dos educandos para delinear e monitorar as suas próprias atividades. Assim, de maneira a estimular a metacognição, o docente possui toda a vantagem em multiplicar as circunstâncias propensas a investigação, as resoluções de problemas difíceis no trajeto dos quais o indivíduo é induzido a optar entre diferentes opções e a precipitar as decorrências dessas alternativas. Apenas esse gênero de atividade pode oferecer ao educando - principalmente se vier a apresentar dificuldades - a oportunidade de dirigir de forma direcionada as suas próprias ações cognitivas (MACNAMARA DS, 2007).

Com isto, entende-se que a eficiência da aprendizagem não se torna dependente somente da idade, experiência e grau de intelectualidade, entretanto, igualmente da obtenção de estratégias cognitivas e metacognitivas que permitam ao educando delinear e monitorar a sua aprendizagem escolar; ou seja, que admitam a tomada de consciência dos procedimentos que usa para aprender e a tomada de decisões adequadas acerca de quais estratégias usar em cada atividade e, também, avaliar a sua eficiência, modificando-as, quando não dão os resultados almejados (SPINILLO AG, 2008).

Frente a este ponto de vista, para a aprendizagem, torna-se necessário aprender como fazer para aprender, que não satisfaz somente fazer e saber, entretanto, é necessário saber como se faz para saber e como se faz para fazer. Portanto, a metacognição pode ser enxergada como a competência crucial de que depende a aprendizagem, com certeza a mais importante (COELHO CLG e CORREA J, 2010). E, finalmente, o estudante se utiliza de estratégias metacognitivas quando este analisa, revê e reflete acerca 
da aprendizagem, eleva a importância e a aplicabilidade das informações. Sendo assim, as ações cognitivas que podem ser vistas como um apoio para as estratégias metacognitivas no Ensino Médio, seriam realizar uma lista dos tópicos mais importantes do texto, realizar um resumo para organizar as informações julgadas como mais importantes, listar as informações que compreendeu com maior facilidade, dentre outras (HODGERS LVSD, 2010).

É preciso conscientizar e disseminar a visão do idioma enquanto um bem cultural a ser preservado. A leitura e a escrita, portanto, são essenciais para o progresso humanal, ao proporcionar a estimulação de diversas áreas do encéfalo entre as funções da fala, visão e audição de vocábulos, permitindo tanto o autoconhecimento do indivíduo quanto a sua interação com o ambiente. Enquanto aporte neurocognitivo aos estudos linguísticos, a neurolinguística contribui sobre o processamento textual nos hemisférios cerebrais e disseminação de áreas de ativação (RIBEIRO LB, et al., 2019).

Apesar de ativações neurais mudarem constantemente, aquelas que se espalham em redes associativas podem ser capturadas com maior facilidade, incluindo quando são relativas à representação de palavras, (RIBEIRO LB, et al., 2019). Tal processo é de grande interesse científico e que precisa ser ainda enfatizado e analisado com cautela em outros projetos de pesquisa.

Espera-se, a partir das atividades desenvolvidas pelo projeto, realizadas de forma democrática e participativa, contribuir também na preparação dos discentes para exames de vestibulares e de concursos públicos, além da iniciação científica, transformação do aluno, autonomia de estudo e preparação para a vida, dando continuidade à iniciativa junto às instituições de educação em Belém-Pará.

\section{CONSIDERAÇÕES FINAIS}

Foi possível concluir que a utilização das estratégias metacognitivas se trata de um precioso recurso secundário para o reforço de conexões sinápticas pelo fenômeno da neuroplasticidade e aprendizagem. Com isto, torna-se possível defender a necessidade de se ressaltar a compreensão escrita com estratégias metacognitivas, enquanto recurso de suma importância para a promoção do pleno processo educativo na assimilação de novos conteúdos linguísticos. Esta prática pode ser estimulada pelo docente mediante procedimentos didático-pedagógicos simples, que não exigem muito tempo para a aplicação, mas com efeitos capazes de extrapolar as fronteiras da sala de aula.

\section{REFERÊNCIAS}

1. ALMEIDA LS, et al. (Orgs.), Avaliação Psicológica: Formas e Contextos. Braga: Psiqulíbrios, 2008; 10p.

2. CASA DA CIÊNCIA. Rebuscando o português: por uma neuroplasticidade diferente. 2017.

3. COELHO CLG, CORREA J. Desenvolvimento da compreensão leitora através do monitoramento da leitura. Psicologia: Reflexão e Crítica, 2010, 23, 580p.

4. D'ALFONSO S. Review of information: A very short introduction. Essays in Philosophy, 2010, 11: 2-10.

5. GUERRA LB. O diálogo entre a neurociência e a educação: da euforia aos desafios e possibilidades. Revista Interlocução, 2011, v. 4, n. 4, p. $3-12$.

6. HODGES LVSD. Um estudo sobre a influência da metodologia on-line em compreensão de textos. Tese de Doutorado em Psicologia Cognitiva - Programa de Pós-Graduação em Psicologia Cognitiva. Recife: Universidade Federal de Pernambuco, 2010; 40p.

7. JOLY MC, et al. Uso de estratégias de leitura por alunos do Ensino Médio. Ribeirão Preto. Paidéia: Revista Cadernos de Psicologia e Educação, 2006, v. 34, p. 204-214.

8. MARINI JAS, JOLY MCR. A. A leitura no Ensino Médio e o uso das estratégias metacognitivas. Estudos e Pesquisas em Psicologia (UERJ), 2008, v. 8; 46p.

9. MCNAMARA DS (Org.) Reading comprehension strategies: theories, interventions, and technologies. New York: Lawrence Erlbaum Associates, 2007; 289p.

10. OECD. PISA 2015 Results in Focus, PISA in Focus, No. 67, OECD Publishing, Paris, 2016.

11. REIS A, et al. Neuroplasticidade: Os efeitos de aprendizagens específicas no cérebro humano. In NUNES $C$ e JESUS S (Eds.), Temas actuais em Psicologia. Faro: Universidade do Algarve, 2009; pp. 11 - 26. 
12. RIBEIRO LB. Complexidade semântica e habilidade de decodificação: um modelo quantitativo da compreensão de textos denotativos em língua portuguesa baseado na teoria da informação. 2018. 74 p. Dissertação (Mestrado) Universidade Federal do Pará, Instituto de Ciências Biológicas, Belém, 2018. Programa de Pós-Graduação em Neurociências Biologia Celular.

13. RIBEIRO LB, et al. Abordagem neurolinguística do texto narrativo: Um enfoque teórico. Revista Científica Multidisciplinar Núcleo do Conhecimento, 2019, ano 04, ed. 06, vol. 11: pp. 41-46. ISSN: 2448-0959.

14. RIBEIRO LB, et al. Oficina de arte visual baseada na obra clássica O Pequeno Príncipe voltada a jovens autistas e neurotípicos com o auxílio das neurociências. Revista Eletrônica Acervo Científico, 2019, v. 7, p. e2177.

15. RIBEIRO LB, et al. Quantification of textual comprehension difficulty with an information theory-based algorithm. Palgrave Commun 5, 103 (2019) doi:10.1057/s41599-019-0311-0.

16. RIBEIRO C. Metacognição: Um Apoio ao Processo de Aprendizagem. Universidade Católica portuguesa, 2003.

17. SHANNON CE. A mathematical theory of communication. Bell Syst Tech J, 1948, 27: 379-423, 623-656.

18. SILVA AB e SIQUEIRA VP. Sequência didática: uma proposta de ensino-aprendizagem antinormativa. Gláuks Revista de Letras e Artes, 2017, [S.I.], v. 16, n. 01, p. 242-250. ISSN 2318-7131.

19. SPINILLO AG. O leitor e o texto: desenvolvendo a compreensão de textos na sala de aula. Revista Interamericana de Psicología/Interamerican Journal of Psychology, 2008, San Juan, v. 42, n. 1; 39p. 